\title{
COMPLIANCE WITH GLUTEN-FREE DIET IN A SELECTED GROUP OF CELIAC CHILDREN IN THE SLOVAK REPUBLIC
}

\author{
Kvetoslava Rimárová1, Erik Dorko', Jana Diabelková1, Zlatana Sulinová1, Pavol Makovický2, Jana Baková3, \\ Tomáš Uhrin ${ }^{4}$, Andrej Jenča ${ }^{5}$, Janka Jenčová ${ }^{5}$, Adriána Petrášová ${ }^{5}$, Andrej Jenča Jr. ${ }^{5}$, Jozef Jenča ${ }^{6}$ \\ ${ }^{1}$ Department of Public Health and Hygiene, Faculty of Medicine, Pavol Jozef Šafárik University in Košice, Košice, Slovak Republic \\ ${ }^{2}$ Department of Biology, Faculty of Education, J. Selye University, Komárno, Slovak Republic \\ ${ }^{3} 1$ st Department of Surgery, Faculty of Medicine, Pavol Jozef Šafárik University in Košice and Louis Pasteur University Hospital, Košice, \\ Slovak Republic \\ ${ }^{4}$ Department of Dermatology, Faculty Hospital of J. A. Reiman, Prešov, Slovak Republic \\ ${ }^{5}$ Department of Stomatology and Maxilofacial Surgery, Faculty of Medicine, Pavol Jozef Šafárik University in Košice \\ and Louis Pasteur University Hospital, Košice, Slovak Republic \\ ${ }^{6}$ Department of Otorhinolaryngology, Faculty Hospital of J. A. Reiman, Prešov, Slovak Republic
}

\section{SUMMARY}

Objective: Celiac disease (CD) is a chronic long-term disease with autoimmune disorder connected to an allergic reaction to the molecule of gluten. $C D$ is manifested in persons who are genetically predisposed. The only therapy for $C D$ is a strong gluten-free (GF) diet. The aim of our study was to follow the adherence to the gluten-free diet in the selected group of parents and caregivers of children with $C D$, and to compare factors influencing the adherence to GF diet and therefore influencing also clinical symptoms of CD. We compared and examined important food-related activities as well, by using a personal questionnaire in the group of $\mathrm{CD}$ children's parents or caregivers.

Methods: We designed a cross-sectional study; 325 parents or caregivers of children with $C D$ were recruited in the sample. CD was confirmed by the European Society for Paediatric Gastroenterology Hepatology and Nutrition (ESPGHAN) criteria. The anonymous questionnaires were collected at summer camps within period data 2012-2016 and followed factors which might have an influence on compliance with GF diet, according to parents' opinions.

Results: Adherence to GF diet was statistically significantly higher among girls compared to boys. Parents' questionnaires confirmed that younger group of children and children with the family history of $\mathrm{CD}$ had statistically higher compliance with GF diet. Parents with higher education confirmed better adherence to GF diet, statistical analyses confirmed higher adherence in mother's education compared to father's education. Duration of $C D$, socio-demographic factors of parents - age of parent, gender of parent, and residency were not statistically significant in terms of compliance with the diet.

Conclusions: Our study confirmed important factors influencing adherence to the GF diet, which are connected to the symptoms and consequences of CD. The assessment of parents' opinions and burden on the families of children with celiac disease should be also reflected in the evaluation of patient's status. Important is also the role of parents in order to facilitate and support clinical interventions and prevention of CD.

Key words: celiac disease, parent's opinion, risk factors, adherence, gluten-free diet

Address for correspondence: K. Rimárová, Department of Public Health and Hygiene, Faculty of Medicine, Pavol Jozef Šafárik University in Košice, Šrobárova 2, 04180 Košice, Slovak Republic. E-mail: kvetoslava.rimarova@upjs.sk

https://doi.org/10.21101/cejph.a5369

\section{INTRODUCTION}

Celiac disease (CD) is chronic autoimmune disorder of the small intestine which occurs in genetically predisposed people of all ages from middle infancy onward. CD prevalence is from 0.3 to $1.3 \%$ of the population (1-3). Genetically, the susceptibility is present in subjects carrying HLA DQ2 and HLA DQ8 (3). Clinical symptoms of active CD include pain and discomfort in the digestive tract, chronic constipation or diarrhoea, growth stunting, anaemia, fatigue, abdominal distention, malabsorption, loss of appetite, and among children failure to grow normally. Child celiac disease usually starts in the infant age. Vitamins, minerals and nutrients deficiencies are often noted in patients with celiac disease due to the reduced ability of the small intestine to properly absorb nutrients from food (4). CD is demanding for treatment, with a lifelong gluten-free (GF) diet. Currently, GF diet is the only effective treatment for celiac disease (5). No medication exists that will prevent damage or prevent the intestine from attacking the gut when the gluten is present. Strict adherence to the GF diet allows the intestines to heal, which usually leads to restoration and resolution of all symptoms in most cases and, depending on how soon the diet is begun, can also eliminate the higher risk 
of disease connected with CD sequels, which are osteoporosis, anaemia, autoimmune diseases, nutrient deficiency diseases, intestinal cancer and in some cases, sterility (6). The diet can be cumbersome with difficulties to maintain strict recommendations; but failure to comply with the diet may cause relapse of CD.

$\mathrm{CD}$ belongs to chronic non-infectious diseases. Chronic diseases are in most cases responsible for significant changes in the quality of life in terms of important clinical, social, psychological, and economic burdens on the patient's family, on the group of parents, caregivers or on the group of relatives (7). In the case of $\mathrm{CD}$, adherence to gluten-free diet is vital for health outcomes and persisting symptoms of CD. Adherence to diet also depends on the type of personality, age of the patients, gender, family and social surrounding (8). When the person is coming into adolescence period, there is social and peer pressure, including an increasing independence from the parents, which can lead to difficulties in adhering to the strict GF diet. There have been several scientific studies taking into account quality of life in the group of CD patients. Some of them focused on adult population $(8,9)$, while some on children's group $(10,11)$.

We suppose that it is very important to discover and confirm the extent to which celiac children suffer as a result of the disease. Compared to other chronic disease connected with handicaps (wheelchair, chronic devastating muscular disorders) - CD patients seem to have equal quality of life, comparable to an average population (11). Scientific studies comparing quality of life of patients with the celiac disease have conflicting and different results. Some studies (11-14) confirmed that quality of life was almost on the same level as the general population, other reference studies confirm decreased quality of life, particularly in mental and social areas (15). Taghir et al. (16) confirmed in their study a better quality of life among celiac children with higher compliance with GF diet.

The aim of our study was to compare factors influencing adherence to GF diet and therefore influencing also clinical symptoms of CD in the selected group of celiac children in Slovakia. We compared impact of selected factors on adherence to gluten-free diet and also we described and analysed important food-related activities by using personal questionnaire in the group of parents or caregivers.

\section{MATERIALS AND METHODS}

We designed cross-sectional observational anonymous questionnaires study. In the sample, we recruited 325 volunteers, parents or caregivers of children at age 9-15 years, with diagnosis of celiac diseases confirmed by ESPGHAN (European Society for Paediatric Gastroenterology Hepatology and Nutrition) criteria $(17,18)$. The questionnaires were collected in 2012-2016 during a specialized summer camp for children with gluten-free diet. Self-administered questionnaire were filled out at the admission to the summer camp. In the selection process of children we avoided repeating evaluation of the child who was at the camp repeatedly. In the selected group of celiac children, there were parents of 223 girls and 102 boys. Parents obtained questionnaires to assess demographics factors and possible factors influencing compliance with GF diet. Questionnaires were anonymous. Some questions have been added specifically concerning lifestyle, chronic additional symptoms in children, lengths of gluten-free diet and adherence to diet. Since CD genetically partly inherits susceptibility to gluten, the study also compared the importance of presence of CD among relatives.

We have also identified food-related activities which reflect satisfaction of the parents with situation about GF products - food market, accessibility, labelling and financially covering the costs via health insurance companies in the country. For evaluation of compliance with gluten-free diet we used socio-economic and demographic parameters, measurement of serum antibodies due problems of blood taking at the camp stay wasn't performed.

The database was analyzed using the Statistical Package for the Social Sciences IBM-SPSS, version 17.0. Food related activities were expressed as frequency tables. For the descriptive analysis, absolute and relative frequencies were calculated. Odds Ratio (OR) with 95\% Confidence Interval (CI) were used to compare impact of selected factors on compliance with diet. The rejection level established for the null hypothesis was lower than or equal to $0.05(5 \%)$.

\section{RESULTS}

Questionnaires data from 325 parents of children with CD have been analysed in the study. In total, there were parents' or caregivers' questionnaires from 102 boys and 223 girls with mean age of 10.12 years (Table 1). Younger children (9-11 years old) composed $60.3 \%$ of the group, older children (12-15 years old) were represented in $39.7 \%$. Presence of CD disease among relatives - family history of CD - (parent, grandparent, sibling, cousin) was confirmed in $12.9 \%$ of the group. Long duration of CD (7-14 years) was present in $38.2 \%$ of the children, but most of the children had shorter duration ( $0-6$ years) of the disease at $61.8 \%$ (Table 1).

Strict adherence to the GF diet was maintained by $69.2 \%$ of children, less frequent was lower compliance with the diet (non-strict diet or some gluten) - 30.8\%. Parents reported gastrointestinal symptoms in majority of children $58.8 \%$. Prevalence of elementary education among parents was low - maternal elementary education was reported in $5.8 \%$ cases, fathers had elementary education in $5.2 \%$ cases (Table 1 ).

Important factors which can have an influence on adherence to GF diet are presented in Table 2. OR are calculated for the group of girls, younger children, children with family history of CD, children with short duration of disease, children with presence of gastrointestinal symptoms. OR for level of parents' education (Table 3) compared risk for adherence to GF diet in the group of children where one parent had elementary versus higher education.

Compliance with GF diet (Table 2) was statistically significantly higher among girls compared to boys $\mathrm{OR}=1.87(\mathrm{p}<0.05)$. It means that girls adhered to GF diet better than boys. Also, younger group of children had better compliance with gluten-free diet compared to the older group $\mathrm{OR}=2.08(\mathrm{p}<0.01)$. Adherence to the diet was statistically significantly higher $(\mathrm{OR}=4.88$; $95 \%$ CI 1.67-14.07; $\mathrm{p}<0.01)$ in the group of children with family history of CD among relatives. Our statistical analysis did not confirm the fact that duration of the disease is an important factor which may influence the compliance with gluten-free diet, but better results in the GF diet compliance are amongst the children 
with shorter duration of disease. Gastro-intestinal symptoms were not present mostly in CD children keeping strong GF diet (92.5\%) compared to the group with non-strict gluten free diet. The impact of GF diet maintenance was statistically highly significant $(\mathrm{OR}=$ $0.09 ; 95 \%$ CI $0.04-0.18 ; \mathrm{p}<0.01$ ) with gastrointestinal symptoms (Table 2). Better adherence to GF diet was among children without gastro-intestinal symptoms $(\mathrm{p}<0.0001)-92.5 \%$ of children without gastrointestinal symptom kept strict GF diet, compared to $52.9 \%$ children with symptoms on strict GF diet.

High statistical significance for low adherence to GF diet $(p<0.001)$ was in the group of children with elementary-educated mothers (Table 3 ) compared to the group of mothers with higher education (secondary and university) $-\mathrm{OR}=0.18$. Similar, but lower statistical significance $(\mathrm{p}<0.05)$ was confirmed among elementary versus higher education of fathers in the group of
CD children. Demographic factors related to parents or caregivers - age of the parent, gender of the parent, rural versus urban residence, number of siblings in the family - did not have any significant impact on adherence to GF diet.

Our results also confirmed findings about barriers to maintain gluten-free diet (Table 4). The main barriers, reported by the parents and caregivers in the questionnaires, were the following: availability of GF products in restaurants ( $85 \%$ of dissatisfaction), understanding GF diet in the group of public restaurant staff $(85 \%)$, food situation at schools ( $81 \%)$, high cost of GF products at the market $(77 \%)$, problems with GF diet when travelling $(76 \%)$ etc. Lower complains about barriers to dietary compliance included: availability of GF products in the country, social pressure from peers, teachers approach, insufficient labelling and lack of information about GF diet.

Table 1. Basic characteristic of celiac children group $(N=325)$

\begin{tabular}{|l|l|c|}
\hline \multirow{2}{*}{ Characteristic } & Categorization & \multicolumn{1}{|c|}{$\begin{array}{c}\text { Total } \\
\text { (\%) }\end{array}$} \\
\hline \multirow{2}{*}{ Gender } & Girls & $223(68.6)$ \\
\cline { 2 - 3 } & Boys & $102(31.4)$ \\
\hline \multirow{2}{*}{ Age } & Younger (9-11 years) & $196(60.3)$ \\
\cline { 2 - 3 } & Older (12-15 years) & $124(39.7)$ \\
\hline \multirow{2}{*}{ Family history of celiac disease } & Yes & $42(12.9)$ \\
\cline { 2 - 3 } & No & $283(87.1)$ \\
\hline \multirow{2}{*}{ Duration of disease } & Short (0-6 years) & $201(61.8)$ \\
\cline { 2 - 3 } & Long (7-14 years) & $124(38.2)$ \\
\hline \multirow{2}{*}{ Gastro-intestinal symptoms } & Yes & $191(58.8)$ \\
\cline { 2 - 3 } & No & $134(41.2)$ \\
\hline \multirow{2}{*}{ Strict GF diet } & Yes & $225(69.2)$ \\
\cline { 2 - 3 } & No & $100(30.8)$ \\
\hline \multirow{2}{*}{ Level of mother's education } & Elementary & $19(5.8)$ \\
\cline { 2 - 3 } & Secondary + university & $306(94.2)$ \\
\hline \multirow{2}{*}{ Level of father's education } & Elementary & $17(5.2)$ \\
\cline { 2 - 3 } & Secondary + university & $308(94.8)$ \\
\hline
\end{tabular}

Table 2. OR of compliance with gluten-free diet by risk factors $(N=325)$

\begin{tabular}{|c|c|c|c|c|c|c|}
\hline Factor & Category & $\mathrm{n}(\%)$ & $\begin{array}{c}\text { Strict GF diet } \\
\mathrm{n}(\%)\end{array}$ & $\begin{array}{c}\text { Non-strict GF diet } \\
\mathrm{n}(\%)\end{array}$ & OR $(95 \% \mathrm{Cl})$ & $\mathrm{p}$-value \\
\hline \multirow{2}{*}{ Gender of child } & Girls & $223(68.6)$ & $164(73.5)$ & $59(26.5)$ & \multirow{2}{*}{$1.87(1.14-3.07)$} & \multirow{2}{*}{$0.013^{*}$} \\
\hline & Boys & $102(31.4)$ & $61(59.8)$ & $41(40.2)$ & & \\
\hline \multirow{2}{*}{ Age of child } & Younger (9-11 years) & $196(60.3)$ & $148(75.5)$ & $48(24.5)$ & \multirow{2}{*}{$2.08(1.29-3.36)$} & \multirow{2}{*}{$0.003^{* *}$} \\
\hline & Older (12-15 years) & $129(39.7)$ & $77(59.7)$ & $52(40.3)$ & & \\
\hline \multirow{2}{*}{$\begin{array}{l}\text { Family history of } \\
\text { celiac disease }\end{array}$} & Yes & $42(12.9)$ & $38(98.5)$ & $4(9.5)$ & \multirow{2}{*}{$4.88(1.69-14.07)$} & \multirow{2}{*}{$0.003^{* \star}$} \\
\hline & No & $283(87.1)$ & $187(66.1)$ & $96(33.9)$ & & \\
\hline \multirow{2}{*}{ Duration of disease } & Short (0-6 years) & $201(61.8)$ & $137(70.9)$ & $64(31.8)$ & \multirow{2}{*}{$0.88(0.54-1.43)$} & \multirow{2}{*}{$\begin{array}{c}0.594 \\
\text { n.s. }\end{array}$} \\
\hline & Long (7-14 years) & $124(38.2)$ & $88(71.0)$ & $36(29.0)$ & & \\
\hline \multirow{2}{*}{$\begin{array}{l}\text { Gastro-intestinal } \\
\text { symptoms }\end{array}$} & Yes & $191(58.8)$ & $101(52.9)$ & $90(47.1)$ & \multirow{2}{*}{$0.09(0.04-0.18)$} & \multirow{2}{*}{$<0.001^{* * *}$} \\
\hline & No & $134(41.2)$ & $124(92.5)$ & $10(7.5)$ & & \\
\hline
\end{tabular}

${ }^{*} p<0.05 ;{ }^{* *} p<0.01,{ }^{* * *} p<0.001 ;$ n.s. - not significant ; GF - gluten-free 
Table 3. OR of compliance with gluten-free diet by parental education $(N=325)$

\begin{tabular}{|c|c|c|c|c|c|c|}
\hline Factor & Category & $\mathrm{n}(\%)$ & $\begin{array}{c}\text { Strict GF } \\
\text { diet } \\
n(\%)\end{array}$ & $\begin{array}{c}\text { Non-strict GF } \\
\text { diet } \\
n(\%)\end{array}$ & OR $(95 \% \mathrm{Cl})$ & $p$-value \\
\hline \multirow[b]{2}{*}{ Level of mother's education } & Elementary & $19(5.8)$ & $6(31.6)$ & $13(68.4)$ & \multirow[b]{2}{*}{$0.18(0.07-0.50)$} & \multirow[b]{2}{*}{$0.0009^{* * *}$} \\
\hline & $\begin{array}{l}\text { Secondary + } \\
\text { university }\end{array}$ & $306(94.2)$ & $219(71.6)$ & $87(28.4)$ & & \\
\hline \multirow[b]{2}{*}{ Level of father's education } & Elementary & $17(5.2)$ & $7(41.2)$ & $10(58.8)$ & \multirow[b]{2}{*}{$0.29(0.11-0.78)$} & \multirow[b]{2}{*}{$0.015^{\star}$} \\
\hline & $\begin{array}{l}\text { Secondary + } \\
\text { university }\end{array}$ & $308(94.8)$ & $218(70.1)$ & $90(29.2)$ & & \\
\hline
\end{tabular}

${ }^{*} p<0.05 ;{ }^{* * *} p<0.001 ;$ GF - gluten-free

Table 4. Barriers to dietary compliance reported by patients with celiac disease $(N=325)$

\begin{tabular}{|l|l|}
\hline Barriers & Percentage of unsatisfied respondents (parents) \\
\hline Availability of GF products in public restaurants & 85 \\
\hline Understanding of GF diet in restaurants staff & 85 \\
\hline Food situation at schools & 81 \\
\hline Price of GF products & 77 \\
\hline Problems with GF diet traveling in the Slovakia & 76 \\
\hline Coverage of GF products with health insurance system & 61 \\
\hline Problems with GF diet traveling abroad & 59 \\
\hline Availability of GF products & 57 \\
\hline Group (peers) behaviour and social pressure & 40 \\
\hline Understanding of GF diet at school staff - teachers & 38 \\
\hline Insufficient labelling & 21 \\
\hline Lack of information about GF diet & 15 \\
\hline
\end{tabular}

GF - gluten-free

\section{DISCUSSION}

Parents of celiac children could be at risk of over-treatment of the psychological, social and physical impacts of the disease on child's development. It is important that parents of celiac children let their children be heard about their perceived quality of life.

Our scientific article represents a report to focus on factors influencing the adherence to the GF diet among parents and caregivers of children with CD. Globally, diagnosis of each chronic disease in the childhood leads to concern of parents. The observational questionnaires study of the celiac children parents were collected at summer camp for celiac children. Each child has legislatively confirmed CD and confirmed evidence to be registered as handicapped at the Social Insurance Company of Slovak republic. Approval of CD was clinically based on the ESPGHAN criteria $(17,18)$.

Slovak republic does not have a national registry of chronic celiac disease and also there is no mandatory population screening blood tests for CD. Considering that gluten-free products in Slovak republic - as a country belonging to EU - are under Regulation EU No 1169/2011 of the European Parliament and of the Council on the provision of food information to consumers Directive (19), which states the gluten is on the list of major food allergens.
In 2012 , there has been an attempt to receive summary reports from all gastroenterology outpatient departments (paediatric and also adult) about number of registered patients with $\mathrm{CD}$. The estimated amount of celiac patients in 2012 in Slovak republic was approximately 13.463 what means occurrence rate of $1: 404$. From these data we can suppose that celiac disease is under-diagnosed in Slovak population (20).

In 2014, we published a study about adherence to gluten free diet among children using specific child questionnaires (21). Results of our study revealed that compliance with GF diet is statistically significantly higher among girls compared to boys. Also, younger group of children have a little bit higher compliance with the gluten-free diet compared to older group, but OR was not statistically significant. Our outputs did not confirm the fact that duration of the disease is an important factor which may influence the compliance with the gluten-free diet, but more significant is the relationship to GF diet compliance in children with shorter duration of disease.

Celiac disease is a female-predominant disease, with a female to male ratio of $2: 1$ or $3: 1$ (22). Ratio of girls compared to boys in our sample was $2.18: 1$, which is similar to the literature reference $(22,23)$. Girls or females have usually better adherence to GF diet compared to boys/males (23) - this output was also confirmed in our analysis. The above mentioned studies also confirmed several factors connected with reduced health-related 
quality of life: gender, age of diagnosis, teenage diet, absence of symptoms, education of parents and also income per capita in the family (23).

Age of the child is an important factor influencing GF diet compliance $(11,23,24)$. Mean age of children in our sample group was almost identical to the study of Rashid et al. (11). Young children with celiac disease adhered better to GF diet because of parental influence, the situation remains complex in adolescents (24). The results of the study (24) found decreased dietary compliance in children above 9 years of age. The percentage of compliant children dropped from $75.92 \%$ in children $>2-5$ years to $41.37 \%$ in children above 9 years of age. Therefore our outputs are also in accordance with study of Gar and Gupta (24). Compliance rate of $93 \%$ at 12 years of child's age was decreasing to $76 \%$ in the age group $15-17$ years (25). There are various reasons which may be responsible for increasing the non-compliance with increasing age of the child, including more intensive social interactions, increased peer group pressure, increased outdoor activities, and need for experimentation $(24,25)$.

However, another study (26) also followed socio-demographic factors influencing CD including gender, age at participation, age at diagnosis of $\mathrm{CD}$, length of time on a GF diet, educational achievement, and employment status. Those factors were not found to be correlated with adherence to GF diet.

Mother's education was considered as a significant factor related to the GF diet compliance. Usually, the mother in the family is responsible for buying and preparation of food items. With her level of education and knowledge, she is able to identify better which food item is gluten-free (24). Another study showed similar correlation of both (mother's and father's) parental knowledge and education with dietary compliance with the GF diet (27). There is more evidence that compliance with the gluten-free diet is improved in those who are more knowledgeable and educated about celiac disease and about GF diet. Study also shows that parents' positive attitude towards the child's condition is associated with higher compliance (27). Statistical analysis of our study also highlights that higher degree of compliance is noted when parents have better education and therefore wider knowledge about celiac disease and the glutencontaining products, understand the importance of gluten-free diet for their child's overall growth and development, and are able to distinguish gluten-containing from gluten-free food.

There has been improved availability of GF products over the last two decades, which may have positive influence on compliance with GF diet. Despite this factor, there could be external obstacles and barriers to maintain GF diet (28), which can have an impact on quality of life. Our results are in agreement with Meyer and Rosenblum scoping review (2017), where the metaanalysis of the studies confirmed the following aspects as the most frequent problems and barriers: eating at public restaurants, social events, birthday's parties and also traveling. Scoping review (29) also confirmed frequent barriers to maintain the GF diet, such as food availability, activities and events at schools. Outputs of our study confirmed high prices of gluten-free product as another barrier as well, which is particularly associated with low-income situation in the country and with low-level average salaries, while the European and internationals GF food producers put equal prices on their products across all markets.
GF diet should be followed lifelong and permanently, yet there is proven economic impact and financial burden, which could be in some families an important factor. Slovak healthcare system has very special, but only partial financial subsidies for registered gluten-free products from health insurance companies. The client/patient can get the basic, registered GF products from the pharmacy, based on the prescribed receipts from a specialist (gastroenterologist) or general practitioner.

Conditions for maintaining gluten free diet are globally in great improvement due good food market and labelling policy in EU and worldwide. Detection of food contaminants is improved through valid legislation of EU, which is very helpful. Producers of GF products in EU preserve the integrity of GF products; they do not use wheat starch, as it may contain residual gluten. Wheat in the products is usually replaced with corn, potato or rice starches, which are naturally gluten-free. Information about the GF diet and products can be acquired via medical and healthcare staff, via literature and internet resources, while the few non-governmental organisations which are directly helping persons with GF diet are also very helpful. In the European Union and also in Slovakia, the gluten-free market of food products is in rapid development in the past years and the market has sufficient amount of gluten-free products as well. Since 2012, the valid EU Regulation - Directive Annex II - Substances or products causing allergies or intolerance has been in place (19).

\section{Limitations of the Study}

Selection of the study population among parents and caregivers who attended the summer camp could lead to a small bias because these parents could be more alert about patients' health than other group of celiac children parents. Also, the data outputs might be limited due to analysis only inside of the sample of celiac children parents. We did not include control group, trying to avoid bias, in case when the control subjects wouldn't be properly selected. Also, in the case of celiac children, it would be extremely difficult to define a control group, because the GF diet needs very strong adherence and has specific issues impacting the quality of life. The analysis of antibodies wasn't performed due ethical reason and problems to collect blood samples at summer camp.

\section{CONCLUSION}

Celiac disease is described mostly as a chronic disorder starting in childhood period. The only possible treatment of CD is strong, consistent and life-long gluten-free diet. Our study revealed some import social and demographic factors which might influence the adherence of the person to the demanding gluten-free diet. Outputs of the study confirmed important factors influencing adherence to GF diet which is connected with symptoms and consequences of CD: statistically significantly better adherence to GF diet was in the group of girls, among the children with family history of $\mathrm{CD}$, younger group of children, and in families with higher education of mother and father, and among the children without gastrointestinal symptoms.

Preventive measures, which have been proposed in the past, are factors accounting for real decline of celiac disease or for delayed diagnosis. These include changes in infant feeding lower 
antigenicity of baby food formulas and later consequent introduction of gluten in the infant diet. Also, the quality of life of celiac children has tendency to be improved due to a wider production of gluten-free products and also due to food products labelling.

\section{Acknowledgement}

This work was supported by national grant KEGA 007UPJŠ-4/2018 principal investigator Kvetoslava Rimárová.

\section{Conflict of Interests}

None declared

\section{REFERENCES}

1. Byass P, Kahn K, Ivarsson A. The global burden of childhood coeliac disease: a neglected component of diarrhoeal mortality? PLoS One. 2011;6(7):e22774. doi: 10.1371/journal.pone.0022774.

2. Ciccocioppo R, Kruzliak P, Cangemi GC, Pohanka M, Betti E, Lauret $\mathrm{E}$, et al. The spectrum of differences between childhood and adulthood celiac disease. Nutrients. 2015;7(10):8733-51.

3. Ludvigsson JF, Leffler DA, Bai JC, Biagi F, Fasano A, Green PH, et al. The Oslo definitions for coeliac disease and related terms. Gut. 2013;62(1):43-52.

4. Di Sabatino A, Corazza GR. Celiac disease. Lancet. 2009; 373(9673): 1480-93.

5. Kupper C. Dietary guidelines and implementation for celiac disease. Gastroenterology. 2005;128(4 Suppl 1):S121-7.

6. Treem WR. Emerging concepts in celiac disease. Curr Opin Pediatr. 2004;16(5):552-9.

7. Streisand R, Monaghan M. Young children with type 1 diabetes: challenges, research, and future directions. Curr Diab Rep. 2014;14(9):520. doi: 10.1007/s11892-014-0520-2.

8. Black JL, Orfilia C. Impact of celiac disease on dietary habits and quality of life. J Hum Diet. 2011;24(6):582-7.

9. Ciacci C, Lavarone A, Mazzacca G, De Rosa A. Depressive symtoms in adult coeliac disease. Scand J Gastroenterol. 1998 Mar;33(3):247-50.

10. Grech PL, Richards J, McLaren S. Psychological sequelae and quality of life in coeliac disease. J Pediatr Gastroenterol Nutr. 2000;31 Suppl 3:6.

11. Rashid M, Cranney A, Zarkadas M, Graham ID, Switzer C, Case S, et al. Celiac disease: evaluation of the diagnosis and dietary compliance in Canadian children. Pediatrics. 2005;116(6):e754-9.

12. Hallert C, Grännö C, Hultén S, Midhagen G, Ström M, Svensson H, et al. Living with coeliac disease: controlled study of the burden of illness. Scand J Gastroenterol. 2002;37(1):39-42.

13. Roos S, Karner A, Hallert C. Psychological well-being of adult coeliac patients treated for 10 years. Dig Liver Dis. 2006;38:177-80.

14. Zarkadas M, Cranney A, Case S, Molloy M, Switzer C, Graham ID, et al. The impact of gluten-free diet on adults with coeliac disease: results of a national survey. J Hum Nutr Diet. 2006;19(1):41-9.

15. Altobelli E, Paduano R, Gentile T, Caloisi C, Marziliano C, Necozione $\mathrm{S}$, et al. Health-related quality of life in children and adolescents with celiac disease: survey of a population from central Italy. Health Qual Life Outcomes. 2013 Dec 5;11:204. doi: 10.1186/1477-7525-11-204.

16. Taghdir M, Honar N, Mazloomi SM, Sepandi M, Ashourpour M, Salehi M. Dietary compliance in Iranian children and adolescents with celiac disease. J Multidiscip Health. 2016; 9:365-70.

17. ESPGHAN guidelines diagnosis coeliac disease children/adolescents. An evidence-based approach [Internet]. 2010 [cited 2019 Jan 5]. Available from: http://www.celiac-disease-consortium.nl/attachments/080 Mearin $\% 20$ ESPGHAN\%20CD\%20WG\%20voor\%20CDC\%20november\%202010.pdf.

18. Husby S, Koletzko S, Korponay-Szabó IR, Mearin ML, Phillips A, Shamir R, et. al.; ESPGHAN Working Group on Coeliac Disease Diagnosis; ESPGHAN Gastroenterology Committee; European Society for Pediatric Gastroenterology, Hepatology, and Nutrition. European Society for Pediatric Gastroenterology, Hepatology, and Nutrition guidelines for the diagnosis of coeliac disease. J Pediatr Gastroenterol Nutr. 2012 Jan:54(1):136-60.

19. Regulation EU No 1169/2011 of the European Parliament and of the Council of 25 October 2011 on the provision of food information to consumers amending Regulations (EC) No 1924/2006 and (EC) No 1925/2006 of the European Parliament and of the Council, and repealing Commission Directive 87/250/EEC, Council Directive 90/496/EEC, Commission Directive 1999/10/EC, Directive 2000/13/EC of the European Parliament and of the Council, Commission Directives 2002/67/EC and 2008/5/EC and Commission Regulation (EC) No 608/2004. Off J Eur Union. 2011 Nov 22; (L 304).

20. Pekarkova B, et al. Celiac disease in Slovak Republic: books of abstracts Gastroforum; 2012. (In Slovak.)

21. Rimarova K. Celiac diseases - global demographic context and Slovakia. Int J Celiac Dis. 2013;1(1):17-8.

22. Ciacci C, Cirillo M, Sollazzo R, Savino G, Sabbatini F, Mazzacca G. Gender and clinical presentation in adult celiac disease. Scand J Gastroenterol. 1995;30(11):1077-81.

23. Ciacci C, D’Agate C, De Rosa A, Franzese C, Errichiello S, Gasperi $\mathrm{V}$, et al. Self-rated quality of life in celiatic disease. Digest Dis Sci. 2003;48(11):2216-20.

24. Garg A, Gupta R. Predictors of compliance to gluten-free diet in children with celiac disease. Int Sch Res Notices. 2014 Aug 28;2014:248402. doi: $10.1155 / 2014 / 248402$

25. Ljungman G, Myrdal U. Compliance in teenagers with coeliac disease - a Swedish follow-up study. Acta Pediatrica. 1993;82(3):235-8.

26. Leffler DA, Edwards-George J, Dennis M, Schuppan D, Cook F, Franko DL, et al. Factors that influence adherence to a gluten-free diet in adults with celiac disease. Dig Dis Sci. 2008 Jun;53(6):1573-81.

27. Anson O, Weizman Z, Zeevi N. Celiac disease: parental knowledge and attitudes of dietary compliance. Pediatrics. 1990; 85(1):98-103.

28. MacCulloch K, Rashid M. Factors affecting adherence to a gluten-free die in children with celiac disease. Paediatr Child Health. 2014;19(6):305-9.

29. Meyer S, Rosenblum S. Activities, participation and quality of life concepts in children and adolescents with celiac disease: a scoping review. Nutrients. 2017 Aug 24;9(9). pii: E929. 